Educación Física y Ciencia, vol. 20, nº 1, e044, 2018. ISSN 2314-2561

Universidad Nacional de La Plata.

Facultad de Humanidades y Ciencias de la Educación.

Departamento de Educación Física

\title{
Educação Corporal: uma análise comparada entre a Colômbia e a Argentina
}

Almeida, Felipe Quintão de; Eusse, Karen Lorena Gil

Cita sugerida: Almeida, F. Q., Eusse, K. L. G. (2018). Educação Corporal: uma análise comparada entre a Colômbia e a Argentina. Educación Física y Ciencia, 20(1), e044. https://doi.org/10.24215/23142561e044 


\title{
Educação Corporal: uma análise comparada entre a Colômbia e a Argentina
}

Body Education: a comparative analysis between Colombia and Argentina

\author{
Felipe Quintão de Almeida \\ Universidade Federal do Espirito-Santo, Brasil \\ fqalmeida@hotmail.com
}

Karen Lorena Gil Eusse

Universidade Federal do Espirito-Santo, Brasil

kalogil@yahoo.es

\section{Resumo:}

Este artigo oferece uma descrição de duas perspectivas críticas da tradição da Educação Física na América do Sul. Ambas, apesar de situadas em países diferentes (Colômbia e Argentina), utilizam a mesma expressão: Educação Corporal. Em termos metodológicos, realiza-se uma revisão sistemática dos escritos de dois representes dessas correntes: Luz Elena Gallo e Ricardo Crisorio. Após a descrição, evidencia as afinidades mas, também, as diferenças das propostas em análise, ocasião, além disso, para dirigir algumas problematizações sobre elas.

Palavras-Chave: Educação Corporal, Educação Física, Colômbia, Argentina, Corpo.

\section{Abstract:}

This paper describes two critical perspectives on the Physical Education tradition in South America. Both perspectives, although located in different countries (Colombia and Argentina), use the same expression: Body Education. In methodological terms, literature review was conducted on the works by two representative authors of the aforementioned theoretical frameworks: Luz Elena Gallo and Ricardo Crisorio. After describing these perspectives, this paper highlights the similarities and differences between the proposals under analysis and outlines some problematizations regarding both perspectives.

KEYWORDs: Body Education, Physical Education, Colombia, Argentina, Body.

\section{INTRODUÇÃO}

Este artigo está inserido no contexto de uma investigação que objetiva discutir, de um ponto de vista comparado com o Brasil, movimentos de crítica e renovação da Educação Física em três países da América do Sul: Argentina, Colômbia e Uruguai.1 A pesquisa, por sua vez, soma-se aos esforços empreendidos por outros colegas no sentido de conhecer e, algumas vezes, comparar, aspectos diversos da disciplina Educação Física no contexto latino-americano (Bracht \& Crisorio, 2003; Silva \& Bedoya, 2015; Silva \& Bedoya, 2017).

Mais especificamente, este material reflete sobre duas perspectivas teóricas que se apresentam como alternativa à tradição da Educação Física. Ambas, apesar de situadas em dois países (Colômbia e Argentina), respondem pelo mesmo nome: Educação Corporal. A proposta do artigo é cotejar, sem situá-las em relação ao Brasil, os desenvolvimentos teóricos dessas duas "correntes" em seus lugares de origem. Para tanto, vamos tomar em revisão os escritos de dois importantes representantes da Educação Corporal: Luz Elena Gallo (Colômbia) e Ricardo Luis Crisorio (Argentina), porém não ficaremos restritos somente ao que eles escreveram. A estratégia foi privilegiar suas produções considerando a relevância de Gallo e Crisorio no desenvolvimento das propostas.

Organizamos a análise de modo descrever, nos tópicos iniciais, algumas características da Educação Corporal na Colômbia e na Argentina. Nas considerações finais, realizamos o exercício de comparação das duas vertentes, oportunidade, também, para dirigir a elas nossas próprias dúvidas e/ou problematizações. 


\section{A EducaÇão Corporal na Colômbia}

O conceito de Educação Corporal é desenvolvido na Colômbia, principalmente, desde o grupo de pesquisa Estudios en Educación Corporal, coordenado pela professora Luz Elena Gallo, no âmbito do Instituto Universitário de Educación Física da Universidad de Antioquia. Essa perspectiva tem alcançado, no país andino, um espaço cada vez mais reconhecido, sobretudo graças à considerável produção acadêmica disponível sobre o tema, ao reconhecimento do grupo de pesquisa em questão e a presença da corrente no âmbito da pós-graduação. 2

O grupo apresenta três linhas de pesquisa: "Cuerpo-educación-experiencia, Prácticas Corporales en clave (trans)formativa y Subjetividades estéticas y políticas”. A preocupação central dos pesquisadores ali reunidos é a relação entre corpo e educação. Desse modo, "Los problemas de los que se ocupa el grupo están relacionados con las maneras en que las instituciones educativas se ocupan de la educación del cuerpo en el mundo contemporáneo, de las pedagogías de la educación corporal" (García, 2012, s. p). Para desenvolver esse tema, seus integrantes se ampararam em discursos provenientes da História, Sociologia, Arte, Filosofia e Educação, usando, ao mesmo tempo, as seguintes tendências teóricas: a fenomenologia, a antropologia pedagógica, as filosofias da diferença, as teorias da formação em perspectiva filosófica, a experiência estética e a educação como experiência.

García e Correa (2011, p. 96) expõem que o conceito de Educação Corporal corresponde ao anseio de pensar diferente o significado pedagógico do corpo na educação, especialmente quando se constata que o discurso pedagógico tem se preocupado pouco por tematizá-lo e a Educação Física, como matéria escolar, tem se ocupado dele sem, contudo, dar-lhe uma significação pedagógica adequada. Gallo (2010, p. 303), nessas circunstâncias, explica que a ideia do corporal na expressão Educação Corporal faz alusão à necessidade de pensar um corpo indivisível, tarefa não cumprida pela Educação Física, que vem

[...] tematizado el cuerpo desde una visión predominantemente naturalista, entendiéndolo fundamentalmente como res extensa, como cuerpo objeto con una visión simplificadora del 'cuerpo máquina' o del procedimiento anatómico y fisiológico del cuerpo en términos de organicidad, instrumentalización, cosificación, prescripción, entrenamiento, desarrollo, optimizacióny disciplinamiento. De ahí que la Educación Física tome como punto de apoyo imágenes de hombre de la Antropología dualista.

Assim, a Educação Física tem se esquecido do corpo sensível, expressivo, gestual, artístico, criador e criativo em favor de sua versão como "máquina”, "objeto". Com base nessas denúncias, a autora propõe um "giro antropológico-fenomenológico" para a disciplina, fundamentada no argumento de que "El cuerpo, al no ser un objeto, es entonces fenoménico, viviente, actuante [...]” (Gallo, 2007, p. 71).

En perspectiva fenomenológica, mi mano puede tocar cosas y también puede ser tocada, por ello tocar no es sólo la acción del sentido del tacto, sino la tactilidad de todo sentido; mis ojos con los que puedo ver cosas, son a su vez visibles; mis oídos con los que puedo escuchar, a la vez, me permiten escucharme. Por los sentidos es posible experimentar las cosas al tocarlas, escucharlas, verlas, paladearlas; en la percepción hay una reciprocidad, el hecho de tocar es también sentirse tocado y ver es también sentirse visto (Gallo, 2007, p. 71).

Influenciado pela fenomenologia, especialmente a de Merleau-Ponty, Gallo ( 2006, p. 57) opera com a ideia de que o corpo é uma unidade de significação, argumentando que a

[...] la única manera de conocer el cuerpo es vivirlo, experimentarlo y la experiencia que tenemos del cuerpo propio se distiende hacia un mundo significativo. Las percepciones hacen parte de la 'corriente' de las vivencias, de hecho, son expresiones o relaciones de sentido que establece mi cuerpo en el mundo.

Também da fenomenologia se assume que a percepção é uma experiência pré-reflexiva, pois antes do “eu penso"... eu "percebo". Nesse contexto, as práticas corporais são portadores de sentido, já que o movimento é, antes de tudo, simbologia corporal, modo de dizer do corpo próprio que nos comunica algo. A gestualidade nos diz de um corpo que simboliza, expressa, informa, já que “[...] es revelador de un cierto lenguaje del cuerpo 
que puede producir un sentido, un significado, y además de eso, provocar sensaciones” (Gallo, 2012, p. 835). Assim, "[...] la danza, el juego, el caminar y el gesto son lenguajes que se manifiestan de una manera corporal y en perspectiva educativa nos ofrece sentidos a la experiencia de movernos, sentidos que no se reducen a la explicación, justificación o al benefício" (Gallo, 2012, p. 840).

Com base em outros autores da filosofia - como Schiller, Rousseau, Spinoza, Nietzsche, Foucault, Deleuze - Gallo e García (2011) postulam as dimensões ontológica, estética, histórica, poética e lúdica da Educação Corporal. A ontológica é entendida como "[...] un saber del hombre sobre sí mismo, de un hombre que da forma a su vida” (Gallo \& García, 2011, p. 296-297). Aqui, as autoras expõem a potência de gerar um espaço para a experiência na aula. A dimensão estética faz alusão à sensibilidade.3 "La sensibilidad, en términos educativos, pasa por prácticas para el cuidado de sí, por los modos de percibir lo que nos afecta em términos de uma razón-sensible, por aquello que es capaz de emanar el cuerpo para crear" (Gallo \& García, 2011, p. 296-297). A dimensão histórica da Educação Corporal “[...] revelará las descontinuidades y bajezas de los sucesos que constituyeron al cuerpo" (Gallo \& García, 2011, p. 296-297). A dimensão poética, entende que temos mais que um corpo orgânico; temos-somos um corpo que faz experiência, um corpo poético. "La Educación Corporal nos abre unas formas de pensar el cuerpo poético como educación de la sensibilidade, educación del gusto, educación em las prácticas de sí y educación sensorial” (Gallo \& García, 2011, p. 296-297). Finalmente, a dimensão lúdica, que é vinculada ao jogo como possibilidade de criação de si. "El juego es ante todo uma experiência corporal y es uma forma como nosotros nos encontramos ante las cosas, como nos metamorfoseamos, nos deslocamos, nos contradecimos, aspectos que estimulan la estética de nuestra propia existencia" (Gallo \& García, 2011, p. 296-297).

Ao mesmo tempo em que propõem essas dimensões, Gallo e García (2011, p. 297) advogam também alguns sentidos para a Educação Corporal:

Pensar la formación humana como práctica estética, otorgarle un valor superior al cuerpo en la Educación, la educación en el cuidado de sí y de los otros, em el cuerpo como 'gran razon', em los sentidos COM sentido, em um devenir sensible, em las cosas próximas, en el sentimento y por médio del sentimento, en las afecciones, en enseñar a pensar en la fuerza de la voluntad.

O tema experiência é bastante presente na Educação Corporal. A esse respeito explicam Gallo e García (2011, p. 298-299): "Si entendemos la Educación como experiencia, estamos también alejados de um modelo de hombre que señala la idea de ser humano que se debe formar, de aquel hombre que se hace a partir de los presupuestos de uma educación normatizada y positiva”. Uma educação como experiência é uma "educación negativa", conceito que se vincula à "figura del acontecimento", que faz alusão a uma educação performativa, que transforma, que valora a diferença, que se abre ao inesperado e que permite que "algo nos pase" (Gallo, 2011, 2017). Em suma, uma educação assim concebida necessita de "[...] algunos encuentros con el caos que está afuera de lo discursivo, necesita abrirse a las posibilidades que hay en la vida misma, debe permitir encuentros, desplazamientos un acto del devenir constante, de la apertura a los cambios, a las transformaciones" (Gallo \& Martínez, 2015, p. 621). Nessas circunstâncias, o saber que mobiliza a Educação Corporal “[...] será perspectivista, es decir, interpretación de interpretaciones. Instaurará princípios, contenidos, prácticas y formas de desarrollarlos no solo con base en el conocimiento, sino, también con base en la experiência" (Correa, 2011, p. 283). O sujeito que se apropria dessa perspectiva é o da experiência, que é

[...] en potencia, abierto, vulnerable, sensible, expuesto, que se deja decir, afectar, que se detiene a pensar, a mirar, a escuchar, que se demora en el detalle, que suspende la opinión, suspende el automatismo, cultiva la atención, la escucha, la reflexión y la delicadeza, abre los ojos y los oídos. Y, sobre todo, da sentido a lo que somos y a lo que nos passa (Gallo \& García, 2011, p. 301).

Para Gallo (2007), a valorização da experiência permite ver como a própria pessoa experimenta sua corporeidade; assim, as narrativas corporais autobiográficas assumem uma grande importância no âmbito da Educação Corporal, entendidas como 
[...] un retorno al cuerpo desde la palabra y el lenguaje, pues la palabra es solo una forma del cuerpo. Como para la Educación Corporal no hay primacía de una facultad sobre otra, el pensamiento, la razón y la palabra, exponen al cuerpo, dicen del cuerpo precisamente porque la palabra lleva adherido lo intelectivo y lo sensible. La palavra es algo así como lo outro del cuerpo que hace cuerpo. Por medio de la narrativa, el logos se contituye como cuerpo y com ello exaltamos sus linguajes, o, dicho de outro modo, le damos la palabra al cuerpo y queremos escucharlo mediante sus trazos narrativos porque el cuerpo es el que toma la palabra (Gallo \& García, 2011, p. 301).

Segundo Gallo e Martínez (2015, p. 618), à Educação Corporal “[...] interesa cómo esta potencia del cuerpo posee un poder independiente de toda significación o intención preestabelecida”. Nesse contexto, a perspectiva em análise confere centralidade à arte por sua capacidade de estimular a criação (por meio) do corpo. Afirma Gallo (2017) que uma Educação Corporal assim concebida precisa mais de artistas que de professores ou, se preferirem, de "professores artistas",

[...] aquellos que no conozcan límites y que siempre vean en el otro una posibilidad de crear, con la fuerza para llevarlo al límite donde se encuentre con una nueva posibilidad, con la capacidad de moverse rizomáticamente por el estrato de los contenidos y las estructuras para generar nuevos encuentros; pero sobre todo um artista que se desacomode con sus obras, y que su mayor expresión artística sea su vida misma (Gallo \& Martínez, 2015, p. 625).

A Educação Corporal, em sua versão colombiana, procura atrelar, então, a experiência formativa à experiência estética (Gallo, 2012b, 2017; Gallo \& Martínez, 2015). Assim, a aula é um espaço de vida e criação que estimula o hedonismo, o desejo, a imaginação, o sensível, a paixão etc. Trata-se, portanto, de uma formação estética a partir das forças que atravessam o corpo, que é definido por potências e intensidades que lhe permitem expressar uma linguagem da ordem dos afetos.

$\mathrm{Na}$ sequência, após a descrição aqui oferecida, faremos exercício semelhante em relação à perspectiva da Educação Corporal na Argentina.

\section{A EducaÇão Corporal na Argentina}

No caso argentino, a proposta da Educação Corporal está associada à Universidade Nacional de La Plata (UNLP). Segundo esclarece Escudero (2011), foi no Grupo de Estudios en Educación Corporal, coordenado por Ricardo Crisorio e Marcelo Giles e vinculado ao Centro Interdisciplinario Cuerpo, Educación y Sociedad, que se desenvolveu nos últimos anos, na UNLP, a perspectiva da Educação Corporal. Conforme, aliás, o próprio Crisorio (2013), a primeira tentativa de emprego da expressão como conceito técnico se deu em 1997, quando se propôs, sem êxito, o termo para nomear as carreiras de formação de professores de Educação Física naquela universidade. A segunda foi em 2001, quando foi aprovada, pelo Conselho Acadêmico da Faculdade de Humanidades e Ciências da Educação e pelo Conselho Superior da UNLP a Maestría en Educación Corporal, programa em funcionamento desde aquela época.

A opção pela nomenclatura, ainda de acordo com Escudero (2011), tem uma conotação política, no sentido que objetiva contrapor-se à Educação Física. Além disso, visa a incluir, sob a nova denominação, toda uma série de práticas que atravessam o corpo e que não ficam circunscritas, apenas, ao universo da disciplina. A mudança semântica se justificaria pois, segundo Crisorio $(2010,2011,2013)$, a Educação Física tem problematizado a vida dos seres humanos em conexão imediata com a natureza. Nessas circunstâncias, o corpo tem sido representado como morto (körper), objeto de manipulação das diversas ciências que por ele se interessam, como a Fisiologia e a Anatomia. Essa herança se expressa no adjetivo "física", que especifica sua educação. Conforme as palavras de Crisorio (2013, p. 10),

El discurso que constituye y sustenta a la Educación Corporal desplaza el territorio tradicional y los métodos de la Educación Física, excluyendo de los objetos que procura conocer o investigar en primer lugar el cuerpo natural. [...] La Educación Corporal no niega el cuerpo sustancial, extenso, que la fisiología define en su objeto. Pero lo entiende como una construcción particular de una disciplina particular, producida con las herramientas generales de la ciencia moderna, y rehúsa el legado de ese cuerpo que el siglo XIX hizo a la Educación Física. 
Esse legado a que Crisorio (2013) se refere é compreendido no seio daquilo que Michel Foucault, referência nevrálgica no âmbito dos estudos da Educação Corporal, chamou de biopolítica, cujo objeto é o corpoespécie, o corpo-vivente, suporte dos processos biológicos para a inserção controlada dos corpos no aparato produtivo, condicionando a população aos processos econômicos do desenvolvimento do capitalismo. Para ele (2003, 2015a), o advento da Educação Física, no século XIX, é consequência desse processo de estatização da vida biologicamente considerada, que fez da vida nua, para empregar o conceito agambiano, 4 o objeto supremo da política. Esse discurso se renova ao longo do século XX, por exemplo, no conceito da "atividade física e saúde", que segue considerando o corpo na sua dimensão "natural” e como dispositivo biopolítico de controle da população.

A despedida dessa tradição passa, assim, não apenas pelo abandono da expressão Educação Física, mas torna imperiosa a necessidade de um dispositivo para pensar o corpo e sua educação de forma que "transcenda", por assim dizer, o paradigma (biopolítico) que tem, historicamente, caracterizado a tradição da disciplina. Para esse discurso renovado, adjetivado de Educação Corporal,

[...] el cuerpo orgánico natural está perdido. En tanto unidad real, sustancial y carente de alteridad, es el producto del discurso occidental respecto de él, igual que en cuanto superficie o volumen cerrados que definen un interior y un exterior (cf. Crisorio, 2010: cap. 3 ). Por todo eso, para la educación corporal, lejos de pertenecer a la naturaleza, el cuerpo es de la cultura y tiene una historia en la que hay que indagar, no para saber qué o cómo ha sido sino para elaborar un concepto de cuerpo nuevo más que un nuevo concepto de cuerpo (Crisorio, 2013, p. 13).

O corpo da Educação Corporal, portanto, não é físico nem biológico. A “defisicalização" (Crisorio, 2013) nela pressuposta realiza uma inflexão em direção à cultura, inscrevendo o corpo na ordem do "simbólico" (Crisorio, 2013). Crisorio, inspirado em Lacan, afirma que o corpo é um "regalo da linguagem" (Crisorio, 2010, 2011, 2017; Crisorio \& Escudero, 2012).

Ese cuerpo que creen suyo es un 'regalo del lenguaje', dice Lacan (2002, p. 280), y no dice un disparate pues, en efecto, nada sino el lenguaje otorga al cuerpo intuitivo, sensible (intuido, sentido), su carácter de cuerpo, identifica sus partes, las articula y relaciona entre ellas, y lo otorga así al ser que en él se constituye y que no sabe que si no pudiera hablar no se constituiría un cuerpo para él (los animales no tienen cuerpo, son cuerpo, u organismo) (Crisorio, 2017, p. 184).

O corpo próprio, portanto, é uma construção simbólica dada no registro das práticas sociais e culturais. Isso não significa, todavia, que ele careça de materialidade, pois “[...] su constitución como objeto evidencia los efectos de verdad que los discursos y las prácticas tienen en el cuerpo y por tanto la efectividad con la que el mismo opera en la realidad social" (Crisorio \& Escudero, 2012, p. 2).

As "coisas", afirmou Crisorio (2015a), não são antes que as palavras, ou seja, o corpo não é antes dos enunciados que dirigimos a ele. Segundo essa perspectiva,

El conocimiento como construcción alcanza al cuerpo y al movimiento, construyéndolos y dotándolos de significación, lo que hace que todo estudio del cuerpo y del movimento deba incluir el estudio de las significaciones que lo marcan aún desde antes de constituirse en cuerpo y em movimiento, significaciones que, a su vez, forman parte de la red de significaciones que constituye la cultura de una sociedad dada en un momento dado. Es obvio que esta problemática toca de cerca a la educación física y a toda la educación corporal (Crisorio, 2015b).

Volvamos ahora al cuerpo para afirmar que el cuerpo se construye. Según esto, el cuerpo es secundario: el cuerpo pertenece a la realidad en tanto, desde Freud, la realidade se construye; es decir, no se nace con un cuerpo. Existe un organismo, qué duda cabe, como existe un sistema nervioso, quién lo dudaría, y huesos, músculos y articulaciones. Pero nada de eso es el cuerpo, el cuerpo no pertenece a lo real. Debo decir, incluso, que ni siquiera podemos afirmar que el organismo, el sistema nervioso, los huesos, músculos y articulaciones pertenezcan a lo real estrictamente, aunque no pueda profundizar aquí ese análisis. Entre estas realidades y lo real media la actividad construccionista del conocimiento humano: lo real es, en rigor, incognoscible (Crisorio, 1998, p. 5).

Crisorio $(1998,2011)$ é crítico da compreensão pela qual é possível um “[...] conocimiento directo de un cuerpo real a partir de la pura experiencia y el puro ejercicio perceptivo” (Crisorio, 2015b). Não crê, portanto, em sua “[...] percepción inmediata, es decir, sin la mediación de instrumentos externos pero, 
fundamentalmente, sin la intercesión de la palavra" (Crisorio, 2011, p. 91). Discorda, portanto, da ilusão de um "corpo sem palavras", de uma "linguagem corporal" distinta da linguagem ou de mecanismos prélinguísticos de aprendizagem (Crisorio, 1998, 2014) que o tornaria portador de uma experiência originária, cujo sentido está na "coisa", de modo que bastaria lê-la para expressá-la (Crisorio, 2015a). A crítica de Crisorio (2017) a esse respeito dirige-se à crença fenomenológica em que há uma "experiência muda de um sentido mudo". Segue Crisorio (2017, p. 184) afirmando que

[...] empeñados en encontrar la verdad más allá del orden simbólico, se proponen como objetivo lo que suponen más allá del lenguaje, en este caso el cuerpo (en cuanto poseedor de una verdad que el lenguaje no puede formular). Por cierto, a la afirmación de Merleau-Ponty 'soy mi cuerpo' (1993, p. 167) cabe preguntarle ¿quién dice esto, quién lo afirma?

A linguagem, no espectro da Educação Corporal, é entendida como ação, como prática (Crisorio, 1998), cujo sentido não se confunde com intervenção pedagógica ou didática, "[...] sino como dominio de análisis, como el conjunto de los modos de hacer más o menos regulados, más o menos reflexionados, más o menos intencionados" (Crisorio, 2014, p. 344) que configuram a experiência e o pensamento.5 É por isso que Crisorio (2013) entende que o objeto de investigação e de ensino da Educação Corporal é o "corpo da ação", quer dizer, as práticas entendidas como sistemas de ação que tomam por objeto o corpo e querem fazer, pensar ou dizer algo com ele. Em outras palavras, aquelas formas racionalizadas e regulares de comportamento que constituem o corpo (Escudero, 2011). Daí, também, a opção pela expressão "prática corporal” para caracterizar "[...] las prácticas históricas, por ende políticas, que toman por objeto al cuerpo y no se considera equivalente de actividades físicas o de movimiento humano" (Crisorio \& Escudero, 2012, p. 3).

Como ensinar as práticas corporais assim compreendidas? Sem pretender oferecer uma "moral do maestro", um “dever ser" ou, então, um "manual de passos" a seguir, Crisorio e Escudero (2012, p. 6-7) creem que é necessário explicitar algumas considerações a respeito de "como conduzir" no âmbito dessa aposta teórico-política. Assim,

[...] en el registro de la educación del cuerpo y en el marco de la propuesta de una educación corporal tenemos que pensar dos elementos para arriesgar uma sustancia ética, por un lado el hecho de que la educación corporal esta orientada a la formación de formadores y que el núcleo fuerte de la educación corporal es proponer un nuevo cuerpo a partir de su inclusión en el orden simbólico. Creemos que la apuesta de particularizar al sujeto y universalizar al contenido opera como marco en el cual oferecer modos de sujeción, mostrando como formador el modo elegido (enseñar cosas y saberes de modo tal que enseñen formas de pensar y de aproximarse a las cosas y los saberes) y que el pensamiento es una forma posible y necesaria para construir el trabajo ético, el pensamento como experiencia y como ejercicio de la educación del cuerpo.

Em outro texto, Crisorio (2015b), e mesmo utilizando a expressão Educação Física, conclui que essa substância ética implica uma formação que "prepare para a experiência", quer dizer, que instrumentalize os educadores corporais para elaborar suas experiências, sejam de investigação, sejam de exercício profissional. Portanto, uma teoria da prática da Educação Física deve recuperar a experiência corporal-educativa, explicála e comunicá-la, refletindo sobre o campo das práticas corporais (Crisorio, 2003). Nessa direção, Crisorio (2003, p. 52) conclui que uma teoria assim adjetivada, ainda que precise liberar-se da alienação que uma visão tradicional de ciência tem submetido a Educação Física, "[...] deve fazer aderindo à forma científica de explicar”, cuja característica, continua Crisorio (2003), é deixar sempre aberto e incompleto seu programa explicativo. Nessa direção,

[...] habrá que fundar lo que se dice en algo más que en la creencia, la convicción o el gusto de cada uno, o en la reputada evidencia científica que nadie vio (porque la ciencia trabaja con teorías, no con evidencias), analizando las condiciones de producción de las distintas teorías, su coherencia lógica, su pertinencia al campo, debatiendo 'con las armas de la ciencia', como quería Bourdieu (única forma de hacer progresar la ciencia en un campo dado, por caso el nuestro) y ateniéndonos a los resultados del trabajo riguroso, más que a las altisonantes voces de supuestos sabios o de audaces inovadores (Crisorio, 2015b, p. 38). 


\section{CONSIDERAÇÕES FINAIS}

Descrevemos, nos tópicos anteriores, algumas características da Educação Corporal na Colômbia e na Argentina. Doravante, faremos o exercício de compará-las, identificando suas afinidades mas, também, suas diferenças. Será ocasião, além disso, para endereçar nossas próprias problematizações às abordagens em análise.

Um primeiro aspecto a destacar é o fato de ambas as perspectivas se colocarem como uma alternativa à Educação Física, motivadas pelo fato de a disciplina, ao longo de sua história, ter fomentado uma forma de organização da corporeidade que disciplinou e subjugou o corpo, concebendo-o como um objeto, como res extensa, como materialidade morta etc. A Educação Corporal, por seu turno, institui outro modo de pensar o corpo e sua educação, propondo, em vez do corpo físico e natural, outras referências para se viver, experimentar e pensar a corporalidade. Trata-se, assim, de duas abordagens que levam a uma reviravolta no estatuto ontológico e epistemológico do corpo. Pode-se questionar, todavia, se essa redescoberta do corpo já não estava em curso na paisagem cognitiva da própria Educação Física, considerando que o discurso dessa disciplina, nos últimos anos, já denunciou "o que (não)podia o corpo" no seio de sua tradição, ao mesmo tempo em que surgiram propostas, no interior do campo, no sentido de abordá-lo de uma forma não fisicalista. Se uma "virada corporalista” aconteceu no âmbito da própria Educação Física, qual a razão para silenciar-se a ela e propor sua substituição pela Educação Corporal?6

Outro aspecto que necessita de maior esclarecimento é o "alcance" da Educação Corporal. A intenção é que ela assuma o lugar da Educação Física na escola? Quais práticas não circunscritas ao universo da Educação Física interessam à Educação Corporal? Trata-se da criação de uma nova disciplina do conhecimento, que substitua a Educação Física como conceito que organiza um campo acadêmico? O propósito é que as formações de professores de Educação Física assumam essa denominação? Qual o lugar dos saberes biodinâmicos (Fisiologia, Anatomia etc.) em seu âmbito? Como ela se relaciona com os saberes das Humanidades? Qual a sua episteme, afinal? Também carece de melhor delimitação o "universo" das práticas corporais que podem ser englobadas pelo termo Educação Corporal, pois tudo pode ser educação do corpo caso não se estabeleça a que dimensão da cultura corresponde o espectro da Educação Corporal. O esporte tradicional compõe essas práticas? Se sim, qual o sentido do seu ensino? As práticas corporais integrativas, com sua visão de corpo não racionalizada, integram o rol de saberes a serem ensinados pela Educação Corporal?

Outro ponto profícuo de comparação diz respeito às referencias teóricas assumidas pelos autores. $\mathrm{O}$ caso que mais "salta aos olhos" é o de Foucault, cujos conceitos (biopolítica, disciplina, acontecimento, práticas, estética da existência, cuidado de si, ética etc.) são recorrentes nos artigos de Gallo e Crisorio. Por sua vez, Deleuze e Nietzsche, nomes associados à chamada "filosofia da diferença", são encontrados nos textos de ambos mas, sobretudo, nas de Gallo. Também Bourdieu, Lacan e Agamben são "nomes" quase certos nos escritos de Crisorio e pouco comuns (o que não significa dizer ausentes) nos textos de Gallo. Já MerleauPonty é uma referência contumaz nos escritos de Gallo e pouco utilizado por Crisorio. Quando comparado com a produção de Crisorio, é notável o ecletismo teórico - nem sempre salutar - nos artigos de Gallo, graças à presença de autores pertencentes a tradições nem sempre coincidentes, como Rosseau, Fichte, Spinoza e Nietzsche, passando por Husserl, Merleau-Ponty, até chegar, além do próprio Foucault, a Deleuze.

O uso de autores comuns não é suficiente, todavia, para que ambos extraiam conclusóes idênticas para a Educação Corporal. Ao contrário, há diferenças importantes entre Gallo e Crisorio. Em relação à colega colombiana, sua proposta resulta numa valorização da experiência sensível, cuja aposta formativa enfatiza uma educação em favor das emoções, paixões, afetos, sentimentos, hedonismo, jogo, prazer, em suma, das forças e potências imanentes ao corpo. Defende-se, também, que a experiência formativa deve se construir à luz da prática estética, de modo que a educação seja um dispositivo para a reinvenção e criação de si, da vida como obra de arte poética (do corpo poético) que é impulsionada por aquilo que se passa no 
âmbito da experiência perceptiva do corpo e que está "afuera de lo discursivo". Não surpreende, assim, a valorização da arte, pois seria ela a experiência humana que melhor poderia desenvolver a compreensão da Educação Corporal como "chave" estética. Como consequência, também, identificamos uma crítica à educação concebida a partir de um dever ser, de normas que impossibilitem, ao contrário, vivenciá-la como acontecimento, como um devir plural e criativo.

No caso de Crisorio, não encontramos o vocabulário de uma Educação Corporal da ordem da sensibilidade, dos afetos, das intensidades que constituem o corpo, sendo a experiência estética seu horizonte. A ênfase recai na necessidade de se conceber o corpo como um dispositivo da cultura, como um "regalo da linguagem". De igual maneira, também, não se defende uma experiência formativa desprovida de um dever ser em favor do devir permanente, pois se advoga, como vimos, a necessidade de um trabalho ético que oriente a formação dos formadores, preparando-os para viver sua experiência corporal na intenção de se construir um novo corpo inscrito na ordem do simbólico. Nesse contexto, em vez da arte, são "as armas da ciência", quer dizer, "as formas científicas de explicar" que deveriam conduzir o educador corporal no ensino das práticas corporais. Em comparação com a corrente colombiana, portanto, a Educação Corporal na Argentina é "racionalista", em vez de se voltar para a experiência sensível, pré-reflexiva.

Outro ponto que distancia Gallo e Crisorio pode ser visto se tomarmos a argumentação de Gallo segundo a qual o corpo é, ele próprio, uma unidade de significação, portador de sentido, possuidor de uma linguagem própria que nos comunica algo antes mesmo de a linguagem tomar posse dele. É a experiência que temos do corpo próprio que se "estende/lança" até o mundo significativo. Sua compreensão de Educação Corporal pressupõe o que para ela se configura como uma potência do corpo, ou seja, o fato de ele possuir sentido antes mesmo de qualquer significação ou intenção preestabelecida (a palavra é somente uma forma do corpo). Nos termos da Educação Corporal defendida por Crisorio, esse potencial codificador do corpo não é possível, já que o autor é um crítico das perspectivas que creem que o corpo é dotado de um sentido que é aquém da linguagem e/ou das práticas de significação a ele direcionadas. Desconsidera, assim, a possibilidade de uma percepção ou de uma experiência que é antes da palavra ou, então, de uma linguagem que emanaria do próprio corpo. Se a perspectiva defendida por Gallo considera a existência de um "corpo fenomenológico", a de Crisorio rechaça essa possibilidade em favor do seu caráter discursivo.

A controvérsia de Gallo e Crisorio sobre este último aspecto pode ser lida a partir da oposição de duas posições: uma construtivista (ou construtivismo social) e outra corporificada ou materialista (Ortega, 2008). A primeira, que se vincula à posição de Crisorio, compreende que a materialidade do corpo é construída de modo que é impossível um acesso natural a ele ou, então, a existência de uma consciência pré-reflexiva. No limite, o corpo, o organismo e a materialidade são incognoscíveis, pois são uma construção social, um efeito do discurso.7 A segunda visão, identificável nos escritos de Gallo nos remete a uma dimensão material e encarnada da corporeidade como uma entidade ativa e intencional que pressupóe uma experiência subjetiva do corpo (fenomenológico). Objeções poderiam ser levantadas a essas duas perspectivas, e é com elas que encerraremos o artigo.

Se aprendemos com Gadamer (2007) que ser que pode ser compreendido é linguagem, é imprescindível reconhecer, como quer Crisorio, que nossa maneira de falar sobre o corpo é socialmente construída. Apesar disso, não deveríamos concluir que a experiência sensorial envolvida no fato de sermos um corpo e, sobretudo, o próprio corpo em sua materialidade, é produto dos discursos que produzimos sobre ele. Essa visão desencarnada da corporeidade (ou a rejeição corporal da corporeidade que pressupóe) desconsidera um potencial de ação do corpo que ultrapassaria sua dimensão discursiva/construtiva. O corpo não apenas sofre ações, não é apenas passivo8 em relação aos discursos que o enunciam, mas toda ação é, ela mesma, uma ação do corpo. De igual maneira, a linguagem não deveria ser compreendida como uma atividade desencarnada, pois a fala sobre o corpo "[...] surge a partir das estruturas corporais, ela já é encarnada. A linguagem não fabrica o corpo, antes o corpo molda a linguagem e as estruturas racionais que usamos para compreender o mundo" (Ortega, 2008, p. 215). 
De certa forma, para citar Bracht (2015), o que está em questão com essa crítica é um retorno ao "corpo fenomenológico" com potencial de ação que não se submete totalmente a uma determinada construção discursiva. Recorrendo a Gil (1997), significa imputar ao corpo uma função ativa ao processo de sua nomeação. Toda a nossa expressividade gestual ou, de maneira geral, corporal, supõe articulações não verbais que investem o corpo, libertando-o para a linguagem. É como se o corpo precisasse se articular préverbalmente para possibilitar significar pela linguagem. Trata-se de um conteúdo não linguístico em potência de verbalização, mas ainda não significado pela linguagem (Almeida, 2012).

Também vale lembrar, contra o construtivismo social do corpo, as advertências de Nietzsche (2001b), para quem toda forma de comunicação, de linguagem, portanto, é uma forma de vulgarização, no sentido de “tornar comum". Por mais longe que alguém leve o conhecimento de si, nada pode ser mais incompleto do que sua imagem da totalidade dos impulsos que o constituem. É por isso que, em última instância, jamais responderemos à pergunta "o que pode um corpo", pois a consciência e a linguagem nunca conseguiriam expressar a "somatória unitária de vivências" de que ele é capaz (Viesenteiner, 2014). Elas, desse modo, nada mais são do que resultado de uma dupla abreviação9 do que pode o corpo, sua espontaneidade. Nietzsche (2001a, p.71) além disso, afirma que as experiências mais fundamentais não são traduzíveis ou tagarelas, pois

O que verdadeiramente nos acontece, não é eloqüente. Ainda que os acontecimentos quisessem, não poderiam comunicarse por si mesmos. Carecem de palavras. Estamos acima das coisas que podemos comunicar por meio de palavras. Em todos os discursos há algum desprezo. Ao que parece, a linguagem não foi inventada a não ser para as coisas medíocres, vulgares, comunicáveis. Com a linguagem, o que fala começa a vulgarizar-se.

No que diz respeito à visão corporificada ou materialista, representada, aqui, pelos textos de Gallo, ela pressupõe a existência, para utilizar as palavras do próprio Crisorio, de uma "experiência muda de um sentido mudo". Assim sendo, não sabemos, de modo satisfatório, como essa "experiência muda de um sentido mudo" se torna compreensível por meio da linguagem. Vale, aqui, dirigir a Gallo as perguntas que realizamos em outro (con)texto: como esse sentido expressivo, anterior à significação, se relaciona com a linguagem? Qual é a osmose que aí se efetiva? Sérgio (1987, p. 94) elabora a pergunta que nos interessa fazer a Gallo: “[...] qual o modo de estudar o sensível (o pré-consciente, como fundo ou horizonte de toda a reflexão) sem tematizá-lo e, por conseguinte, sem a presença, também implícita, da cultura?”. Ele conclui dizendo que “'O trânsito da percepção ao conceito, da zona da pré-constituição à da constituição, foi algo que Merleau-Ponty jamais conseguiu explicar'” (Sérgio, 1987, p. 94). Em suma, como ocorre a passagem da linguagem em estado nascente, como ato instituinte e criativo, para a sua sedimentação, constituída por significações correntes e pelas demais formas de expressão de um dado meio sociocultural? (Almeida, Bracht \& Ghidetti, 2013).

Embora a perspectiva de Gallo realize uma "incorporação" da linguagem, para nós, não se trata mais de ver na "linguagem" do corpo uma camada de sentido que se dá em uma compreensão antepredicativa de um sujeito constituinte ou de um corpo-sujeito operador de sínteses originárias (de onde a linguagem derivaria). Essa compreensão se contrapõe, portanto, ao argumento de Gallo segundo o qual o corpo possui um poder independente de toda significação ou intenção preestabelecida. Sua independência é, por assim dizer, relativa. Aquilo que podemos chamar de pré-verbal não surge, como tal, senão retrospectivamente, pela ação da linguagem sobre a camada de sentido previamente articulada. Assim, não podemos dizer que uma massa de sentido exista antes e independente da linguagem, uma vez que o sentido surge somente em função da relação semiótica, por referência à linguagem que o descreve. Toda a dificuldade, comenta Gil (1996, p. 19), consiste em pensar um não verbal que seja não um pré, mas um postverbal:

É por retroacção e ruptura que a linguagem verbal constitui o não verbal como 'pré-verbal', quer dizer como efetivamente detentor de sentido não exprimível por signos verbais. Acabam-se assim as velhas aporias fenomenológicas do originário antepredicativo e do derivativo verbal: os dois são originários e derivativos ao mesmo tempo, não há linguagem sem uma compreensão antepredicativa do mundo, mas este é impensável sem a acção da linguagem. O não verbal é realmente um post-pré-verbal: se o gesto corporal, por exemplo, é capaz de exprimir, na dança, nuvens de sentido, é porque o corpo diz, nos seus movimentos próprios, um sentido indizível verbalmente que está 'para aquém’ ('pré) da linguagem, que se revela 
desse modo como anunciador da, ou apelando à linguagem. Mas este corpo não verbal ou pré-verbal da gestualidade, só se constitui como (e só faz) sentido porque a linguagem o (e se) constitui com tal: só projectadas no campo lingüístico se abrem as 'lacunas' de sentido dessas 'nuvens' corporais; e só porque a linguagem existe como sistema de signos é que essas lacunas se podem constituir como 'quase-sistemas' singulares, não verbais (que escapam sempre ao sistema).

Essa compreensão do não verbal como post-pré-verbal evitaria as aporias de compreender o gesto corporal independente da linguagem (como um antipredicativo puro, como a coisa em si), como se ela esgotasse todo o seu sentido nos movimentos do corpo e em sua "simbologia”. Essa é uma crença, salvo melhor juízo, presente nos textos de Gallo aqui analisados.

De nossa parte, todavia, agrada-nos a perspectiva de Souza (2015), ao recusar a posição dicotômica que vê, de um lado, o sensível como não humano, obscuro e, de outro, o simbólico, histórico, cultural, em suma, a palavra. Propõe, em seu lugar, um meio-termo tanto da intuição sensível abstrata supostamente imediata, dada e originária, quanto da apreensão e descrição linguísticas aparentemente autonomizadas ou apenas intersubjetivamente sancionadas, que ele denomina linguicentrismo. Sua proposta reconhece o caráter não fundacionista e social do linguicentricismo, mas o faz a partir da sua abertura ao mundo sensível, sem concebêlo como um a priori fundante ou como uma significação corporificada. Sendo assim, Souza defende (2015, p. 357-358), entre as duas opções acima, a prática

[...] livre e criadora sensível, poiésis, aquela de nós enquanto atividade prática e do mundo dela resultante como artefato. Mesmo que a linguagem verbal necessariamente acompanhe e acrescente a tal atividade prática, vasta e desdobrada, como parte de nossos recursos de transitar pelo mundo (mais do que como recurso para representá-lo), seu eventual papel transformador não precisa deixar de ser concebido como, no fim de contas, estreitamente associado à prática humana corpórea sensível - lidadora e, mais ainda, por si mesma relevantemente transformadora e criadora, donde poiética [...]. Antes que a linguagem nos ofereça as metáforas significadoras-tradutoras de uma realidade supostamente bruta, antes que, digamos, ela mapeie humanamente uma realidade a que querem depois nos fazer crer que nunca chegamos (ainda quando, nota bene, em sua maior parte feita por nós), é a prática, logo prática poiética, criadora, que o faz [...]. O que significa também que o mundo não é tão somente a linguagem com que o dizemos, é, em primeiro lugar, o uso que dele fazemos e a prática com que o discriminamos, constituímos e, finalmente, construímos (Souza, 2015, p. 357).

\section{REFERÊNCIAS}

Almeida, F. Q. (2012). Educação física, corpo e epistemologia: uma leitura com o filósofo José Nuno Gil. Atos de Pesquisa em Educação, 7(2), 329-344.

Almeida, F. Q., Bracht, V., \& Ghidetti, F. F. (2013). A presença da fenomenologia na educação física brasileira: implicações para o estudo do corpo e outras problematizações. Educación Física y Ciencia, 15 (2), 1-16.

Bracht, V. Prólogo. In: Ferreira, A. (Org.). (2015) Pensando la educación física como área del conocimiento: problematizaciones pedagógicas del sujeto y el cuerpo (pp. 1-7). Buenos Aires, Argentina: Miño y Dávila.

Bracht, V., \& Crisorio, R. (Org.). (2003). A Educação Física no Brasil e na Argentina: identidade, desafios eperspectivas. São Paulo, Brasil: Autores Associados.

Correa, A. F. (2011). Formación del gusto y cuerpo em perspectiva educativa: uma interpretación a partir de Friedrich Nietzche hacia uma educación corporal. In: Gallo, L. E. (Org.), Aproximaciones pedagógicas al estúdio de la Educación corporal (pp. 235-289). Medellín, Colombia: Funámbulos Editores.

Crisorio, R. L. (1998) Constructivismo, cuerpo y lenguaje (En línea). Educación Física y Ciencia, 4: 75-81. Recuperado de: http://www.memoria.fahce.unlp.edu.ar/art_revistas/pr.117/pr.117.pdf

Crisorio, R. L. (2003). Educação Física e identidade: conhecimento, saber e verdade. In: Bracht, V.; Crisorio, R. (Org.). A Educação Física no Brasil e na Argentina: identidade, desafios e perspectivas (pp. 31-54.). São Paulo, Brasil: Autores Associados.

Crisorio, R. L. (2010) Homero y Platón: Dos paradigmas de la educación corporal (Tesis de posgrado). Presentada en Universidad Nacional de La Plata. Facultad de Humanidades y Ciencias de la Educación para optar al grado 
de Doctor en Ciencias de la Educación. Recuperado de: http://www.memoria.fahce.unlp.edu.ar/tesis/te.432/ te.432.pdf

Crisorio, R. L. (2011). L. Homero y Platón: dos paradigmas de la educación corporal. Educación Física y Ciencia, La Plata, 13, pp. 77-98. Recuperado de: http://www.memoria.fahce.unlp.edu.ar/library?a=d\&c=arti\&d=Jpr5228

Crisorio, R. L. (2013). Educación corporal. Cadernos de Formação da RBCE, 4(2), 9-19.

Crisorio, R. L. (2014). De una semiótica a una hermenéutica en la investigación de las prácticas corporales. Poiesis, $8(14), 334-347$.

Crisorio, R. L. (2015a). Actividad(es) física(s) versus prácticas corporal(es). In: Galak, E. (Org.). Cuerpo, educación, política: tensiones epistémicas, históricas y prácticas (pp. 21-39). Buenos Aires, Argentina: Biblos.

Crisorio, R. L. (2015b). La teoría de las prácticas. Crisorio, R. (Org.). Ideas para pensar la educación del cuerpo (pp. 31-39). La Plata, Argentina: Edulp. Recuperado de: http://www.memoria.fahce.unlp.edu.ar/library?a=d\&c=li bros\&d=Jpm385

Crisorio, R., coordinador (2015). Ideas para pensar la educación del cuerpo. La Plata : EDULP. (Libros de cátedra. Sociales). Recuperado de: http://www.memoria.fahce.unlp.edu.ar/libros/pm.385/pm.385.pdf

Crisorio, R. L.; Escudero, C., coordinadores (2017). Educación del cuerpo : Curriculum, sujeto y saber. La Plata: UNLP. FAHCE. (Cuerpo, educación y sociedade). Recuperado de: http://www.memoria.fahce.unlp.edu.ar/libros/pm $.504 / \mathrm{pm} .504 . \mathrm{pdf}$

Crisorio, R. L.; Escudero, M. C. (2012) Notas para una ética de la Educación corporal (En línea). Trabajo presentado en VII Jornadas de Sociología de la UNLP, 5 al 7 de diciembre de 2012, La Plata, Argentina. Recuperado de: h ttp://www.memoria.fahce.unlp.edu.ar/trab_eventos/ev.1802/ev.1802.pdf

Escudero, C. (2011). Agente, subjetivación y educación corporal: reflexiones metodológicas. Revista Brasileira de Ciências do Esporte, 33(3), 547-558.

Gadamer, H. G. (2007). Verdade e método I: traços fundamentais de uma hermenêutica filosófica. Bragança Paulista, Rio de Janeiro; Brazil: Vozes, Editora Universitária São Francisco.

Galak, E., \& Rodríguez, N. (2007). Metodología de la investigación y educación corporal. Una investigación de las prácticas: análisis del proyecto "Prácticas, normativa teórica y demandas sociales en Educación Física: dificultades para elaborar modelos didácticos especiales". III Jornadas Académicas "Los Nuevos desafíos de la Educación Física y el Deporte". San Fernando, Buenos Aires.

Gallo, L. E. (2006). El ser-corporal-en-el-mundo como punto de partida en la fenomenología de la existencia corpórea. Pensamiento Educativo, Santiago de Chile, 38, pp. 46-62.

Gallo, L. E. (2007a). Apuntes hacia una educación corporal, más allá de la educación física. In: Moreno, W. G., \& Pulido, S. M. Q. Educación cuerpo y ciudad: el cuerpo en las interacciones e instituciones sociales (pp. 69-91). Medellín, Colombia: Funámbulos Editores.

Gallo, L. E. (2007b). Cuatro hermenéuticas que han marcado la Educación Física en Colombia. In: Chaverra, B. E. F., \& Uribe, I. D. P. Aproximaciones epistemológicas y pedagógicas a la educación física: un campo en construcción (pp. 45-69). Medellín, Colombia: Funámbulos,

Gallo, L. E. (2010). Los discursos de la educación física contemporánea. Bogotá, Venezuela: Kinesis.

Gallo, L. E. (2011). La Educación Corporal bajo la figura del acontecimiento. Revista Educación Física y Deporte, 30(2), 505-513.

Gallo, L.E. (2012a). Las prácticas corporales en la Educación Corporal. Revista Brasileira de Ciências do Esporte, 34(4), 825-843.

Gallo, L. E. (2012b). Notas sobre la educación corporal en clave estética. Revista Latinoamericana de Estudios Educativos, 8(2), 11-29.

Gallo, L. E. (2017). Una didáctica performativa para educar (desde) el cuerpo. Revista Brasileira de Ciências do Esporte, 39(2), 199-205.

Gallo, L. E., \& Martínez, L. J. (2015). Lineas pedagógicas para Educación Corporal. Cadernos de Pesquisa, 45(157), 612-629. 
Gallo, L. E., \& García, C. E. (2011). La Educación Corporal em perspectiva pedagógica. In: Gallo, L. E. (Org.). Aproximaciones pedagógicas al estúdio de la educación corporal (pp. 291-303). Medellín, Colombia: Funámbulos Editores.

García, C. E., \& Correa, A. F. (2011). Educación Corporal o el preludio del valor superior del cuerpo. In: Gallo, L. E. (Org.). Aproximaciones pedagógicas al estúdio de la Educación corporal (pp. 63-103). Medellín, Colombia: Funámbulos Editores.

García, C. E. (2012). Estudios en Educación Corporal. Recuperado de: http://estudioseneducacioncorporal.blogspot .com.br/

Gil, J. N. (1996). A imagem-nua e as pequenas percepçôes: estética e metafenomenologia. Lisboa, Portugal: Relógio d'Água.

Gil, J. N. (1997). Metamorfoses do corpo. Lisboa, Portugal: Relógio d'Água.

Giles, M. (2017). Prácticas corporales. In: Crisorio, R. L., \& Escudero, C. (Org.), Educación del cuerpo: curriculum, sujeto y saber (pp. 57-62). La Plata, Argentina: Universidad Nacional de La Plata, Facultad de Humanidades y Ciencias de la Educación. Recuperado de: http://www.memoria.fahce.unlp.edu.ar/library?a=d\&c=libros\&d= Jpm504

Nietzsche, F. (2001a). Crepúsculo dos idolos: ou como filosofar com o martelo. São Paulo, Brazil: Companhia das Letras.

Nietzsche, F. (2001b). Além do bem e do mal:prelúdio a uma filosofia do futuro. São Paulo, Brazil: Companhia de Bolso.

Ortega, F. (2008). O corpo incerto: corporeidade, tecnologias médicas e cultura contemporânea. Rio de Janeiro, Brazil: Garamond.

Sérgio, M. (1987). Para uma epistemologia da motricidade humana: prolegómenos a uma ciéncia do homen! Lisboa, Portugal: Veja.

Silva, A. M., \& Bedoya, V. M. (2015). Formación professional en Educación Física en América Latina: encuentros, diversidades y desafios. Jundiaí, Brazil: Paco Editorial.

Silva, A. M., \& Bedoya, V. M. (2017). Educación Física en América Latina: curriculos y horizontes formativos. Jundiaí, Brazil: Paco Editorial.

Souza, J. C. (2015). O mundo bem nosso: antirrepresentacionismo poiéticopragmático, não linguístico. Cognitio, $16(2), 335-360$.

Viesenteiner, J. L. (2014). O homem como uma somatória unitária de Erlebnisse (vivência) em Nietzsche. Filosofia e Educação, 6(1), 76-94.

\section{Notas}

1 Projeto financiado pela Fundação de Amparo à Pesquisa do Estado do Espírito-Santo (FAPES/Edital 04/2015) e pela Secretaria de Relações Internacionais da Universidade Federal do Espírito-Santo (Edital 03/2016).

2 Não existem na Colômbia, até a data, cursos de Doutorado em Educação Física, mas há, no Curso de Doutorado em Educação da Universidad de Antioquia, a Línea de formación Educación, Cuerpo y Motricidad, oferecida pelos grupos de pesquisa Estudios en Educación Corporal e Cultura Somática, ambos do Instituto Universitário de Educação Física. Esses tematizam a "[...] educación corporal y la motricidad, en perspectiva pedagógica y didáctica” (Doctorado En Educación, 2017, s. pp).

3 Gallo (2007) afirma que a ideia de sensibilidade é primordial na fundamentação do conceito Educação Corporal. A autora acredita que a sensibilidade é uma qualidade que se cultiva no encontro com o outro, encontro possível no espaço pedagógico: "A la Educación Corporal le interesa la posibilidad de potenciar la sensibilidad como una puesta formativa para la constitución de la subjetividade [...]” (Gallo, 2007, p. 84).

4 Giorgio Agamben é outro autor importante no contexto dos estudos da Educação Corporal na Argentina.

5 A influência, aqui, é claramente o conceito de prática em Foucault. Nele podemos encontrar três características que a definem: “[... en primer lugar la 'homogeneidad', es decir, lo que los hombres hacen y la manera en que lo hacen. No las representaciones que tienen de sí mismos ni de las condiciones que los determinan; sino de 'las formas de racionalidad que organizan las maneras de hacer'. En segundo término ubica a la 'sistematicidad', es decir considerar sistemáticamente el saber (las prácticas discursivas), el poder (las relaciones con los otros) y la ética (las relaciones consigo mismo). Por último la 'generalidad', aquellas cuestiones que tengan un carácter recurrente” (Galak \& Rodrigues, 2007, pp. 2). 
6 Giles (2017, p. 59) nos dá uma pista para entender isso: "Si bien la Educación Físico-crítica aportó una mirada más cultural, su insistencia en no abandonar la denominación que le dieron los fundadores, hace sospechar que sus estudios mantienen cierto núcleo duro, una forma de pensar respecto de una relación individuo-medio o individuo-ambiente, propios del siglo XIX y de una epistemología empírico-analítica”. Faltou ao autor (2017), todavia, demonstrar os motivos pelos quais a Educação Física crítica permanece presa ao século XIX e a uma epistemologia empírico-analítica.

7 O comentário de Giles (2017, pp. 59), não muito diferente do de Crisorio (1998), é cabal para expressar esse entendimento: "Yo invitaría a pensar que no se necessita materia para que haya cuerpo, que hay cuerpo cuando hay palabra, el cuerpo está hecho por las palabras, no por carne, huesos músculos y articulaciones”.

8 Não deixa de ser curioso que as práticas corporais que compõem o ensino da Educação Corporal são compreendidas como sistemas de ação que tomam por objeto o corpo e querem fazer, pensar ou dizer algo com ele. Correspondem, assim, a um discurso sobre o corpo (passivo), em vez de uma ação pedagógica com ele

9 Dupla porque a "tomada de consciência” já é uma economia pulsional. Quando comunicada, quer dizer, tornada linguagem, é um processo que resulta já de uma abreviação anterior (um discurso sobre alguma coisa que se passa no corpo).

La aceptación de colaboraciones por parte de la revista implica la cesión no exclusiva de los derechos patrimoniales de los autores a favor del editor, quien permite la reutilización, luego de su edición (postprint), bajo Licencia Creative Commons Atribución-NoComercial-CompartirIgual 4.0 Internacional (https:// creativecommons.org/licenses/by-nc-sa/4.0/). 